\title{
'GOING THE EXTRA MILE' FOR CLIENTS IN A RURAL COMMUNITY: REFLECTION ON AN ETHICAL ISSUE FACED ON FIELDWORK PLACEMENT
}

\author{
Jocelyn Helm and Mary Butler
}

\section{INTRODUCTION}

This article is a reflective piece that discusses an ethical issue faced in practice through the eyes of a student on fieldwork placement. The placement was in a rural community setting, which in itself provided barriers for a particular client who is referred to throughout this article. In order to protect client and therapist anonymity, I have not used any personal names throughout this piece. I have also changed small details about the context, so that these cannot be identified either.

This article reflects on how conflicts of interest operate and asks the ethical question whether or not it is within professional boundaries to 'go the extra mile' to meet a client's needs. In this case, 'going the extra mile' refers to doing more than what is obviously and immediately necessary or expected in order to achieve something. I am not talking about going beyond the scope of professional practice. Instead, I want to challenge accepted notions of efficiency by suggesting that by doing that little bit more, a lot more trust and therapeutic engagement could be created. Another aspect of 'going the extra mile' involves taking responsibility for what is presented in terms of a particular client's immediate needs and making a special effort to meet those needs. The final part of 'going the extra mile' is implicit in terms of what is required when working in a rural context - one always has to travel the extra mile when working rurally.

The ethical concern in question is discussed here in relation to occupational therapy practice and the use of the Quadripartite Ethical Tool (QET) for ethical analysis. The QET consists of four quadrants that aim to analyse ethical issues experienced in professional practice. These are utilitarian analysis, deontological analysis, virtue ethics and axiological ontology (Drolet \& Hudon, 2015). Utilitarian analysis involves assessing the positive and negative consequences of projected actions on all parties involved, and looks specifically at choosing an action that will produce the greatest happiness for the largest number of people. Deontological analysis focuses on the rights and duties of the different parties to ensure that dignity, autonomy and freedom are respected. Virtue ethics focuses on promoting a narrative approach with patients to elicit their point of view so that decisions are meaningful and suited to them. Lastly, analysis based on axiological ontology underlines the importance of health professionals providing treatment that is in accordance with their professional values. In so doing, they can avoid ethical distress and minimise ethical tensions (Drolet \& Hudon, 20I5).

\section{STATEMENT OF CONTEXT}

As an occupational therapy student on fieldwork placements, I have witnessed several behaviours and situations that were positive from an ethical standpoint. However, I have also witnessed situations and behaviours that were unethical. Given a fresh set of eyes in a placement setting and my status as a student, I felt that I was able to pick up 
on ethical concerns that my supervising therapist might have overlooked. My most recent placement was in a rural community, seeing clients both on the ward and in their homes. Since a good deal of time was spent seeing clients in the community, there were often long periods of travel. Having this time with my supervisor when travelling, I was able to develop my ethical knowledge through discussions with her after visiting clients in their homes. One ethical issue that stood out for me arose when my supervisor stated that it would have involved a conflict of interest for her to go the extra mile to meet a client's needs. At the time, her statement made me feel uncomfortable and led me to ask the question: does it actually involve a conflict of interest for a therapist to go the extra mile to meet a clients' needs? In considering this question a number of issues and other questions arose.

\section{CRITICAL REFLECTION ON AN ETHICAL ISSUE}

The ethical issue referred to on my placement arose when visiting a client in the community. He lived in a small rural town of around 200 people, lacking many facilities and about a half-hour drive from a larger town. This client had lost his home in a fire and had sustained severe burns to his hands and arms. He had no partner or family living nearby and was previously living alone with his dogs. He had no insurance, so after being discharged from hospital he moved into a caravan behind a shopfront that he owned. The caravan was run-down, and he had been sleeping on a thin mattress on the floor.

This client needed a shower stool, raised toilet seat and perching frame, explaining why a visit from an occupational therapist was required. When I visited him, he mentioned that he also needed a bed frame as he was cold from sleeping on the caravan floor. In New Zealand, the Salvation Army is often willing to donate beds. He stated that although the organisation had one available, he lacked the resources to pick up the frame himself. He also stated that the nearest branch of the Salvation Army did not deliver outside of their geographical area and that, unfortunately, he was now living outside of this area.

He expressed how angry he was that nobody was willing to help him and how distressed he was that he lacked the resources to pick up the frame himself. Although there were several other things he needed help with, this was one problem that was proving particularly distressing for him. At the time, I wondered why my supervisor had not suggested that we could deliver the bed frame. On the drive back, I asked her if there was a possibility that we could do this for him. However, she stated this would be considered a conflict of interest and would have breached professional boundaries. I wondered what exactly she meant by this action being a conflict of interest, and what professional boundaries would have been breached? My reflections in this article are intended to clarify these questions.

\section{CONFLICT OF INTEREST}

A conflict of interest occurs in a situation in which professional judgment regarding a primary interest may be influenced by a secondary interest (Lemmens \& Singer, 1998). More generally, conflicts of interest involve two contrasting motives that professionals often confront simultaneously - professional responsibilities vs personal or self-interests. In addition, when professional responsibilities clash with self-interest, the two motives tend to be processed differently. Self-interest involves the working of a more automatic influence than do professional responsibilities, which are more likely to be invoked through controlled processing. This differential processing often means that self-interest prevails, even when the person making the decision consciously attempts to comply with the ethical values of their profession (Moore \& Loewenstein, 2004).

However, in this case I was puzzled - in what way would delivering the bed frame involve a conflict of interest? It would be in any caring person's best interest to want to help this man. Could it have been seen as self-interest to use time paid for by the health service to deliver the bed frame, when it is something that a family or other service would normally do? Or could it have been a case of automatic thinking - that delivering the bed would exceed the 
hours of rostered work or interfere with finishing work on time? Looking at this through the utilitarian ethical lens provided by the QET, not taking action could be rationalised in terms who else it may have affected, in terms of an action producing the best outcome for the largest number of people. If we were to spend more time with a patient beyond what was apparently allocated, other people might suffer, as many others were also in need of direct help from an occupational therapist.

\section{FALLING SILENT}

When my supervisor stated that this case involved a conflict of interest, I hesitated to voice my own opinion as I felt it differed from hers. I felt uncomfortable about the situation, but also about speaking my mind, as I was a student in a subordinate position. I thought it was sad as I wanted to say something, or even deliver the bed frame myself outside of placement hours. However, I would overthink the issue and tell myself it was not my place. I also asked myself what the consequences would be if I was to take action independently as a student. Would I fail my placement? Would I have to repeat that year? These questions led me to remain silent about the issue.

Falling silent is a common experience for many students in practice. According to Bradbury-Jones, Sambrook, and Irvine (2007), students often diminish their role on clinical placements, typically stating they are "just a student" and thus creating the perception that it is not within their scope to question their supervisor's practice. In another study, when students accepted this identity of "just being a student," it often led them to believe that they had no voice and they often felt compelled to remain silent (Levett-Jones \& Lathlean, 2009).

\section{DOMAIN OF CONCERN}

As health professionals, there are certain principles which occupational therapists must adhere to. These are set out in the Code of Ethics for Occupational Therapists (The Occupational Therapy Board of New Zealand, 20I5). They include the statement that occupational therapists shall respect the autonomy of clients receiving their service, focusing on the needs of the client while working with them to determine goals and priorities. I feel that this principle is the one most relevant to my ethical concerns in this case, as the client's autonomy was not fully recognised in this situation because no action was taken. In addition to this, the client's expressed need to sleep on a bed frame, rather than on the floor, was not made a priority over the therapist's originally role, which was to provide equipment. I believe that this situation involved an ethical issue because the outcome hindered compliance with occupational therapy's core values.

Of the four ethical approaches described in the QET, the one most relevant to this ethical issue is axiological ontology. Occupational therapy is founded on core values that influence key aspects of therapists' daily practice including their attitudes, behaviours, reasoning and decisions (Drolet, 20I4). One of the core values of occupational therapy is freedom, which is about enabling choice, independence and self-direction for clients (Peloquin, 2007). I felt that in this situation, my client's freedom of choice and independence were not enabled, as he did not have a choice about whether the bed frame was going to be delivered, and he lacked the resources and physical capability to pick up the frame independently.

In addition, one of the core assumptions of occupational therapy is that engagement in occupation enhances people's wellbeing (Hammell \& Iwama, 20II). Part of the occupational therapist's role is to enable engagement in occupation. For this client, having a decent and safe place to sleep would have been the starting point for such enablement, as being safe is a fundamental principle of human life.

Maslow's hierarchy of needs is a five-stage model of human needs; Maslow suggests that lower-level needs should be satisfied at least to some extent before an individual can meet their higher-level needs (Maslow, 1943). At the lower end of the hierarchy are basic needs such as warmth, food, safety and security. As an individual progresses, they move on to satisfy their psychological needs such as the need for relationships, prestige and feelings of 
accomplishment. At the highest level, a person will reach self-fulfilment by achieving their full potential. Maslow's hierarchy of needs suggests that my client needed to feel safe and secure before he could engage in everyday activities and interact with others in a meaningful way.

Virtue ethics, another quadrant of the QET, is also relevant to my ethical problem; this approach concentrates on the therapist as moral agent and the kind of person a therapist ought to be, rather than doing their duty or acting in order to bring about desirable consequences (Brody \& Doukas, 2014). In the case at issue, I feel that this approach was also not fully acknowledged. Rather, I feel that our practice was focused on our role, defined in terms of doing no more than what we were tasked with - to deliver equipment. Let us assume that delivering the bed frame was not part of my supervisor's role, and that if she stepped out of her role there might have been consequences for her. But what would these consequences have been? Could going the extra mile for this client have brought my supervisor and me greater rewards and enhanced our relationship with our client? I feel that if a virtue ethics approach had been recognised in this case, it might have increased the level of trust and cooperation with the client while also leaving us feeling satisfied with our role.

The most important virtue for every health professional is caring (Drolet \& Hudon, 2015). Sometimes the role of an occupational therapist is broad and hard to define, as roles differ from one another and constantly change. However, a holistic approach and a commitment to responding to clients' needs are a key part of every occupational therapists' professional role. A caring attitude can have a marked impact, as the therapist's role can potentially broaden and extend when she or he is willing to go the extra mile (Sachs \& Labovitz, 1994).

In the case under scrutiny, I am not claiming that my supervisor did not care about the client and his quality of life; in this circumstance, it may have been more a question of the time available. However, if this was the case, then my personal view is that we should do everything to make ourselves available to and responsible for patients beyond our perceived professional role. In addition, if defining the boundaries of an occupational therapist's role is difficult because of the broad range of roles the profession includes, then why not do that little bit more? Stepping outside of one's perceived role and going that extra mile offers many advantages. These include satisfying the therapist's own understanding of what is professionally valid, as well as gaining the trust and cooperation of clients which, in turn, will enhance the client-therapist relationship (Sachs \& Labovitz, 1994). Thus, reflecting on my ethical issue, if my supervising therapist and I had stepped out of our professional roles by doing that little bit more, we could have actually achieved a lot more, both for this client and for ourselves.

\section{RURAL PRACTICE}

Having a placement in a rural community may have also been a contributing factor to my ethical dilemma. The unique contexts of rural communities can provide various ethical challenges (Nelson, Pomerantz, Howard, \& Bushy, 2007). My placement revealed one of the common deficits of rural communities - the limited availability and accessibility of other healthcare services. In rural communites, utilisation of healthcare services often requires longer travel times over greater distances than in urban areas (Chan, Hart, \& Goodman, 2007). This was relevant to my ethical issue, as service providers such as charitable organisations were geographically dispersed and required longer driving time and more resources to access them. This meant that more time had to be allocated to each client, as driving time needs to be considered when seeing clients in a rural community.

In this case, one charitable organisation that was not easily accessible was the Salvation Army. The organisation did not deliver outside of its geographical area, and the client's community lay outside of that area. Thus, if we were to deliver the bed frame, my supervisor would need to step outside of her role. In addition, picking up the frame would have required a minimum of an hour and a half's travel time. By contrast, in urban areas most services are readily available and do not usually require significant travel time. If the service provider had offered delivery to this particular location, the occupational therapist may not have been in the position she found herself in or involved in the delivery of the bed frame at all. 


\section{CONCLUSION}

One of the main points I make in this article is that stepping outside of the traditional occupational therapy role and 'going the extra mile' for a client offers a number of advantages - doing that little bit more can achieve a lot more, both for the therapist and the client. I also want to emphasise that on fieldwork placements, students often diminish their role to being "just a student" and hold back from speaking their mind. However, students do have a voice and it is fully within their scope to discuss their opinions with their supervisor.

From my experience and reflecting on this ethical issue, I have developed a more effective understanding of different ethical approaches. I felt very strongly about helping this particular client; my personal beliefs and values contributed to the situation I found myself in, as well as the values of occupational therapy as a profession - two sets of principles which I feel overlap. Overall, this situation has contributed to my understanding of ethical practice in occupational therapy - I now know what I would do if a similar situation was presented in practice.

One question that I still ask myself is: how far should a therapist be willing to go to enable occupation? Initially, I did not think that delivering a bed frame to a client would cause so much ethical discussion. I can confidently say that if I was placed in this situation again, knowing what I know now, I would voice my opinion with no hesitation. This client was seeking help and I walked away, feeling as if I had turned away from someone in need. One thing that has stuck with me is the client's question - "Why can't the people at the Salvation Army put down their hot cup of coffee to help me?"Well, why couldn't we put down our cup of coffee as well, and do everything it took to help this client? I now believe that - not only for this client, but for all clients - a therapist should do whatever it takes in the situation that presents itself, even if this requires them to step outside of their role as conventionally defined. A caring occupational therapist will always go above and beyond the call of duty for their clients.

Jocelyn Helm is in her third year studying Occupational Therapy at the Otago Polytechnic. She enjoys the diverse opportunities there is within the field of Occupational Therapy and the creativity it offers. She is passionate about helping people and empowering others to help themselves to engage not only the essential tasks of everyday life but those occupations that provide people with meaning and happiness.

Mary Butler (10 0000-0003-3365-8995) is professor of occupational therapy at Otago Polytechnic. She researches and teaches about ethical issues that are specific to occupational therapists. She is particularly interested in how context and culture can shape ethical reasoning.

Correspondence to: Jocelyn Helm: Otago Polytechnic, School of Occupational Therapy, Dunedin, New Zealand; Email: helmjrl@student.op.ac.nz 


\section{REFERENCES}

Bradbury-Jones, C., Sambrook, S., \& Irvine, F. (2007). The meaning of empowerment for nursing students: A critical incident study. Journal of Advanced Nursing, 59(4), 342-35 I. http://dx.doi.org/ | 0.1 I I I/j. I 365-2648.2007.0433 I.x

Brody, H., \& Doukas, D. (20I4). Professionalism: A framework to guide medical education. Medical Education, 48(I0), 980-987. https://doi.org/ I0.1 I I I/medu. 12520

Chan, L., Hart, G., \& Goodman, D. C. (2007). Geographic access to health care for rural medicare beneficiaries. The Journal of Rural Health, 22(2), |40-146. https://doi.org/ | 0.1 I I |/j. 1748-0361.2006.00022.x

Drolet, M. J. (20/4). The axiological ontology of occupational therapy: A philosophical analysis. Scandinavian Journal of Occupational Therapy, 2 I (I), 2-10. https://doi.org/10.3109/1 1038128.2013.831118

Drolet, M. J., \& Hudon, A. (2015). Theoretical frameworks used to discuss ethical issues in private physiotherapy practice and proposal of a new ethical tool. Medicine, Health Care, and Philosophy, I 8(1), 5 I-62. https://doi.org/ | 0. I007/s I I0 I 9-0 I 4-9576-7

Hammell, K. R. W., \& Iwama, M. K. (20I2). Well-being and occupational rights: An imperative for critical occupational therapy. Scandinavian Journal of Occupational Therapy, 19(5), 385-394. https://doi.org/1 0.3 109/1 1038 | 28.201 I.61 I 82 I

Lemmens, T., \& Singer, P. A. (1998). Bioethics for clinicians: Conflict of interest in research, education and patient care. Canadian Medical Association Journal, 159(8), 960-965.

Levett-Jones, T., \& Lathlean, J. (2009). 'Don't rock the boat': Nursing students' experiences of conformity and compliance. Nurse Education Today, 29(3), 342-349. http://dx.doi.org/ 10.10 16/j.nedt.2008. 10.009

Maslow, A. H. (1943). A theory of human motivation. Psychological Review, 50(4), 370-396. http://dx.doi.org/I 0. I037/h0054346

Moore, D. A., \& Loewenstein, G. (2004). Self-interest, automaticity, and the psychology of conflict of interest. Social Justice Research, 1 7(2), | 89-202. https://doi.org/ | 0. I023/B:SORE.0000027409.88372.b4

Nelson,W., Pomerantz, A., Howard, K., \& Bushy, A. (2007). A proposed rural healthcare ethics agenda. Journal of Medical Ethics, 33(I), | 36-139. http://dx.doi.org// 0.1 I36/jme.2006.015966

Occupational Therapy Board of New Zealand. (2015). Code of ethics for occupational therapy. Retrieved from https://www.otboard. org.nz/wp-content/uploads/2015/04/CodeofEthics_April20 I5-I.pdf

Peloquin, S. M. (2007). A reconsideration of occupational therapy's core values. The American Journal of Occupational Therapy, 6 I (4), 474-478. https://doi.org/ | 0.50|4/ajot.61.4.474

Sachs, D., \& Labovitz, D. R. (1994). The caring occupational therapist: Scope of professional roles and boundaries. The American Journal of Occupational Therapy, 48(I I), 997-1005. https://doi.org/ | 0.50 I 4/ajot.48.1 I.997 